Vol.27 No.1, June 2021

ISSN (p): 1693-590x, ISSN (e): 2686-4711

DOI: $10.36309 /$ goi.v27i1.139

\title{
Purwarupa Deteksi PH dan EC Larutan Nutrisi Hidroponik Berbasis Internet Of Things
}

\author{
Paryanta $^{* 1}$, Wisnu Wendanto ${ }^{2}$, Putri Mulyani ${ }^{3}$ \\ ${ }^{1}$ Program Studi Teknik Komputer, STMIK AUB, Surakarta, Indonesia \\ ${ }^{2,3}$ Program Studi Sistem Komputer, STMIK AUB, Surakarta, Indonesia \\ e-mail: *1paryanta@stmik-aub.ac.id, ${ }^{2}$ wisnu.wendanto@stmik-aub.ac.id, \\ 3putrimulyanii2311@gmail.com
}

\begin{abstract}
Abstrak
Sistem deteksi pH dan EC di Rainbrow Hidroponik Boyolali masih konvensional, yakni pengecekan dan penstabilan kadar kepekatan larutan nutrisi dilakukan oleh penggiat hidroponik setiap pagi dan sore hari dan penggurasan tandon penampungan juga dilakukan oleh penggiat hidroponik setiap 2 minggu sekali. Oleh karena itu penggiat hidroponik membutuhkan terobosan baru dengan teknik dan proses otomatis agar dapat memonitoring tanaman tanpa mendatangi tempat tanam atau kebun hidroponik. Penelitian ini bertujuan mendeteksi kadar keasaman dan kepekatan air nutrisi menggunakan mikrokontroler Arduino Uno R3 yang dapat mengirimkan data berupa keasaman dan kepekatan larutan nutrisi ke smart phone android yang terhubung. Keasaman dengan sensor $p H$, dan kepekatan dengan sensor EC. Data dari sensor masuk ke Arduino Uno R3 dan ditampilkan di LCD lalu WiFi modul ESP8266 akan mengirimkan data keasaman, dan kepekatan ke smart phone android dengan teknologi Internet of Things (IoT) serta dapat melakukan kontrol pompa penggurasan tandon penampungan via aplikasi mobile. Hasil penelitian ini berupa purwarupa deteksi $p H$ dan EC larutan nutrisi hidroponik berbasis Internet of Things yang bekerja setelah mendapatkan data kadar $\mathrm{pH}, \mathrm{EC}$ dan ketinggian, relay akan menghantarkan arus daya 12 Volt dari adaptor 12 Volt kemudian solenoid valve akan aktif untuk menstabilkan kadar nutrisi didalam bak tanam dengan membuka kran inputan nutrisi hingga kadar EC berada dibatas toleransi. Bila akan menggosongkan atau menguras bak tanam dengan mengklik tombol push button pada aplikasi blynk di android, relay langsung menghantarkan arus daya dari adaptor 12 Volt ke solenoid valve terbuka hingga ketinggian air dibatas minimum. Kesimpulan purwarupa deteksi $p H$ dan EC otomatis telah berhasil dirancang dan dibuat menggunakan arduino uno R3 sebagai pusat pengendali dengan sensor $\mathrm{pH}$ sebagai pendeteksi keasaman dan kepekatan air didalam bak tanam. Alat akan terus bekerja selama terhubung dengan arus listrik, saat tidak terhubung dengan arus listrik maka aliran larutan nutrisi ke pipa penampungan akan berhenti dan berkurangnya larutan nutrisi sesuai tingkat penyerapan tanaman terhadap larutan nutrisi. Data yang masuk ke aplikasi mobile mengandalkan kekuatan sinyal hotspot WiFi untuk megirimkan data keasaman, kepekatan larutan nutrisi, dan kontrol pompa penggurasan.
\end{abstract}

Kata kunci-Hidroponik, Arduino Uno R3, HC-SR04, Sensor Ph, Sensor EC, ESP8266, IoT, Larutan Nutrisi

Abstract
The $p H$ and EC detection system at Rainbrow Hydroponics Boyolali is still conventional, namely checking and stabilizing the concentration of nutrient solution is carried out by hydroponic activists every morning and evening and draining reservoirs is also carried out by hydroponic activists every 2 weeks. Therefore, hydroponic activists need new breakthroughs with automated techniques and processes in order to be able to monitor plants

Received February 27, 2021; Revised March 11, 2021; Accepted March 17, 2021 
without visiting the planting site or hydroponic garden. This study aims to detect the acidity and concentration of nutrient water using the Arduino Uno R3 microcontroller which can send data in the form of acidity and concentration of nutrient solutions to a connected android smart phone. Acidity with $\mathrm{pH}$ sensor, and density with EC sensor. Data from the sensor enters the Arduino Uno R3 and is displayed on the LCD then the ESP8266 WiFi module will send acidity and density data to an android smart phone with Internet of Things (IoT) technology and can control the reservoir drain pump via a mobile application. The results of this study are a prototype of $\mathrm{pH}$ and EC detection of hydroponic nutrient solutions based on the Internet of Things that work after getting data on pH, EC and altitude levels, the relay will deliver 12 Volt power current from a 12 Volt adapter then the solenoid valve will activate to stabilize nutrient levels in the tub. planting by opening the nutrient input valve until the EC level is within the tolerance limit. When you want to empty or drain the planting tank by clicking the push button on the Blynk application on Android, the relay directly delivers power from the 12 Volt adapter to the open solenoid valve to the minimum water level. Conclusion: The prototype of automatic pH and EC detection has been successfully designed and made using Arduino Uno R3 as a control center with a pH sensor as a detector of acidity and water concentration in the planting tank. The tool will continue to work as long as it is connected to an electric current, when it is not connected to an electric current, the flow of nutrient solution to the reservoir pipe will stop and the nutrient solution will decrease according to the level of plant absorption of the nutrient solution. The data that enters the mobile application relies on the signal strength of the WiFi hotspot to transmit data on acidity, nutrient solution concentration, and control of the dewatering pump.

Keywords- Hydroponics, Arduino Uno R3, Ph Sensor, EC Sensor, ESP8266, IoT, Nutrition Solution

\section{PENDAHULUAN}

Hidroponik (hydroponic) merupakan salah satu metode urban farming, yaitu menggunakan air pengganti tanah (soiless) sebagai media tumbuh tanaman. Metode hidroponik dianggap lebih ramah lingkungan dibandingkan metode konvensional (menggunakan tanah), karena hidroponik tidak menyebabkan penurunan kualitas tanah, dan tidak menghasilkan limbah berbahaya bagi lingkungan. Selain itu juga, metode hidroponik penerapannya lebih efisien di daerah yang memiliki ruang hijau terbatas. Hidroponik merupakan solusi pertanian di perkotaan negara maju baik dalam skala industri maupun skala rumahan. Untuk jenis tanaman hidroponik tidak memiliki syarat tertentu, semua tanaman bisa tumbuh pada media air. Namun karena keterbatasan ruang, maka tanaman yang digunakan memiliki ukuran kecil dan menghasilkan dari sisi ekonomi.

Pemberian dan pengecekan nutrisi air masih dilakukan secara manual yaitu penggiat hidroponik mendatangi kebun hidroponik untuk mengecek kondisi nutrisi air. Apabila stok nutrisi yang ada pada tandon telah melewati batas minimal atau sudah berkurang sepertiga dari volume sebelumnya maka diperlukan penambahan larutan nutrisi pada tandon untuk mendapatkan nutrisi yang cukup. Penggunaan TDS meter digunakan untuk pengecekan kadar keasaman dan kepekatan larutan nutrisi dengan mencelupkan alat tersebut kedalam larutan nutrisi yang menjadi media tanam hidroponik selama $10-20$ detik setiap pagi dan sore hari agar tanaman hidroponik memperoleh nutrisi yang cukup. Dengan demikian penggiat hidroponik membutuhkan terobosan baru dengan teknik dan proses secara realtime agar dapat memonitoring tanaman hidroponik tanpa mendatangi kebun hidroponik.

Pada penelitian ini menggunakan modul mikrokontroler Arduino Uno dan aplikasi mobile sebagai user interface, agar arduino dapat berkomunikasi dengan aplikasi pada Android maka diperlukan sistem komunikasi dengan menggunakan modul Wi-fi yaitu ESP8266. Sedangkan instrument yang dapat dikendalikan adalah pompa air yang digunakan untuk 
mengalirkan air dari tandon air ke pipa hidroponik serta aerator yang digunakan untuk membuat gelembung pada larutan nutrisi yang kemudian menyuplai oksigen ke akar tanaman.

Dengan adanya penelitian ini, diharapkan mampu untuk mengoptimalkan budidaya tanaman hidroponik, sehingga dapat membantu penggiat untuk bercocok tanam non konvensional dengan lebih efisien. Sistem monitoring pada penelitian ini juga diharapkan mampu diterapkan pada perkebunan dan tidak terbatas untuk pemakaian skala kecil. Selain itu, dengan adanya penelitian mengenai deteksi $\mathrm{pH}$ dan EC dapat mendukung pengembangan ilmu pengetahuan di bidang teknologi guna mendukung sistem agricultural di Indonesia.

\section{METODE PENELITIAN}

\subsection{Unit Penelitian}

Larutan nutrisi hidroponik sebagai objek penelitiannya, karena air larutan nutrisi hidroponik termasuk masalah utama dalam budidaya hidroponik khususnya di kebun Rimbow Hidroponik yang beralamat di Jl. Tambas Kidul, Dusun Tegalan, Kismoyoso, Ngemplak, Boyolali.

\subsection{Metode pengumpulan data}

1. Metode Wawancara

Dalam wawancara pengumpulan data yang diperoleh secara langsung dari kebun Rimbow Hidroponik lebih tepatnya di Jl. Tambas Kidul, Dusun Tegalan, Desa Kismoyoso, Kecamatan Ngemplak, Kabupaten Boyolali. Penulis melakukan wawancara dengan Owner atau penggiat hidroponik tentang kadar $\mathrm{pH}$ dan kepekatan air larutan, bagaimana proses penambahan larutan hidroponik ke bak tanam setiap harinya, dan proses pembuangan atau penggosongan bak penampungan. Data primer yang dihasilkan penulis dalam melakukan wawancara dengan Rimba Cahyo Prabowo yakni terlihat dalam Tabel 1.

Tabel 1 Data Primer Wawancara

\begin{tabular}{|l|l|l|}
\hline No & Cara Menanam & \multicolumn{1}{|c|}{ Keterangan Proses } \\
\hline 1 & $\begin{array}{l}\text { Benih dan media } \\
\text { tanam hidroponik }\end{array}$ & $\begin{array}{l}\text { Benih tanaman hidroponik disemai diwadah semai atau tray } \\
\text { menggunakan rockwool, sistem pengairan yang digunakan yaitu } \\
\text { water culture system, sistem ini larutan nutrisi tidak } \\
\text { disirkulasikan, hanya dibiarkan pada bak penampungan. }\end{array}$ \\
\hline 2 & $\begin{array}{l}\text { Nutrisi Tanaman } \\
\text { Hidroponik }\end{array}$ & $\begin{array}{l}\text { Untuk pemberian nutrisi disesuaikan dengan jenis tanaman, } \\
\text { untuk jenis tanaman sayur seperti pakcoy dan kangkung } \\
\text { membutuhkan kepekatan nutrisi 1,5-2,0 ms/cm dan memilik pH } \\
\text { netral atau pH 5,5-7. Untuk mengecekan kondisi nutrisi pada } \\
\text { bak tanam dilakukan pada pagi dan sore hari dengan TDS } \\
\text { Meter. }\end{array}$ \\
\hline 3 & $\begin{array}{l}\text { Perawatan } \\
\text { Tanaman }\end{array}$ & $\begin{array}{l}\text { Penambahan nutrisi hidroponik dilakukan saat nilai EC terlalu } \\
\text { rendah atau dibawah 1,5 ms/cm. larutan nutrisi yang digunakan } \\
\text { nutrisi AB Mix. penambahan air biasa dilakukan saat volume air } \\
\text { dibak tanam berada dibawah batas minimum. }\end{array}$ \\
\hline 4 & $\begin{array}{l}\text { Penggurasan Bak } \\
\text { tanam Hidroponik }\end{array}$ & $\begin{array}{l}\text { Penggurasan atau pembuangan larutan nutrisi dilakukan } \\
\text { seminggu sekali untuk mencegah lumut tumbuh di bak tanam } \\
\text { yang dapat mempengaruhi pertumbuhan tanaman. }\end{array}$ \\
\hline
\end{tabular}

\section{Metode Observasi}

Metode observasi mengumpulkan data dengan mengamati secara langsung tentang proses pengecekan $\mathrm{pH}, \mathrm{EC}$, dan penambahan air nutrisi, serta masalah yang akan ditimbulkan dari kondisi atau sistem yang sedang berjalan. 


\subsection{Tahap-Tahap Pengembangan Alat}

Prosedur pengembangan yang digunakan pada purwarupa deteksi $\mathrm{pH}$ dan EC ini adalah menggunakan prosedur pengembangan model purwarupa. Model ini melakukan pendekatan dengan menggambarkan versi awal dari alat untuk kelanjutan alat sesungguhnya yang lebih besar. Tahap-tahapan pengembangan alat dapat dilihat pada Gambar 1 berikut.

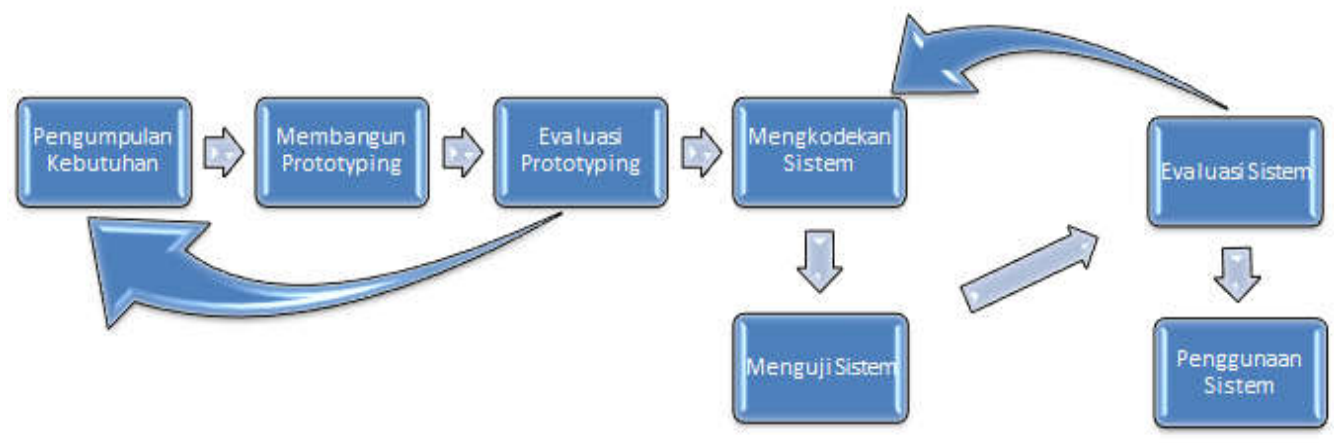

Gambar 1. Tahapan Model Purwarupa

Berikut adalah penjelasan Gambar 1 tahapan-tahapan yang dilakukan didalam metode purwarupa.

a. Pengumpulan Kebutuhan Data

Pada tahap ini peneliti melakukan wawancara dengan owner Rainbrow Hidroponik di Boyolali. Berdasarkan data yang diperoleh dari wawancara yaitu tentang benih dan media tanam, nutrisi hidroponik, perawatan dan pengurasan bak penampungan hidroponik.

b. Pembuatan Purwarupa

Pada tahap ini peneliti melakukan perancangan dan pembuatan alat purwarupa deteksi $\mathrm{pH}$ dan EC, menggambar rangkaian flowchart terhadap solusi dari permasalahan yang ada di Rainbrow Hidroponik yang berkaiatan dengan pengecekan $\mathrm{pH}, \mathrm{EC}$, penambahan Nutrisi, dan pembuangan dengan dokumentasi yang dihasilkan dari tahap desain sistem ini menggunakan aplikasi Fritzing. Komponen yang digunakan berupa mikrokontroler, sensorsensor, aktuator dan lain-lain.

c. Evaluasi Purwarupa

Pada tahap ini melakukan pengukuran atau penilaian tingkat keberhasilan dari pembuatan purwarupa deteksi $\mathrm{pH}$ dan $\mathrm{EC}$, apakah mikrokontroler, sensor, modul WiFi, aktuator sudah aktif dan berfungsi atau diperlukannya perbaikan.

d. Pengkodean Sistem

Peneliti menuliskan program purwarupa deteksi $\mathrm{pH}$ dan EC untuk budidaya tanaman hidroponik menggunakan software Arduino IDE, Bahasa pemrograman $\mathrm{C}$ dan Aplkasi android Blynk sebagai user interface.

e. Pengujian Sistem

Melakukan testing terhadap sistem yang telah dibuat. Pengujian sistem menggunakan air biasa dan Nutrisi AB mix.

f. Evaluasi Sistem

Pada tahap ini penulis melakukan pengkajian ulang terhadap sistem dan kemudian diperbaiki sesuai rancangan flowchart sistem yang telah dibuat.

g. Penggunaan Sistem

Tahapan ini dikatakan selesai dalam pembuatan sebuah alat dan sistem, maka alat dan sistem siap digunakan oleh user.

\subsection{Diagram Blok sistem}

Diagram blok merupakan gambaran umum mengenai prinsip kerja smart farming. Secara umum kerja purwarupa deteksi $\mathrm{pH}$ dan EC ini dapat dilihat pada diagram blok yang ditujukan pada Gambar 2. 


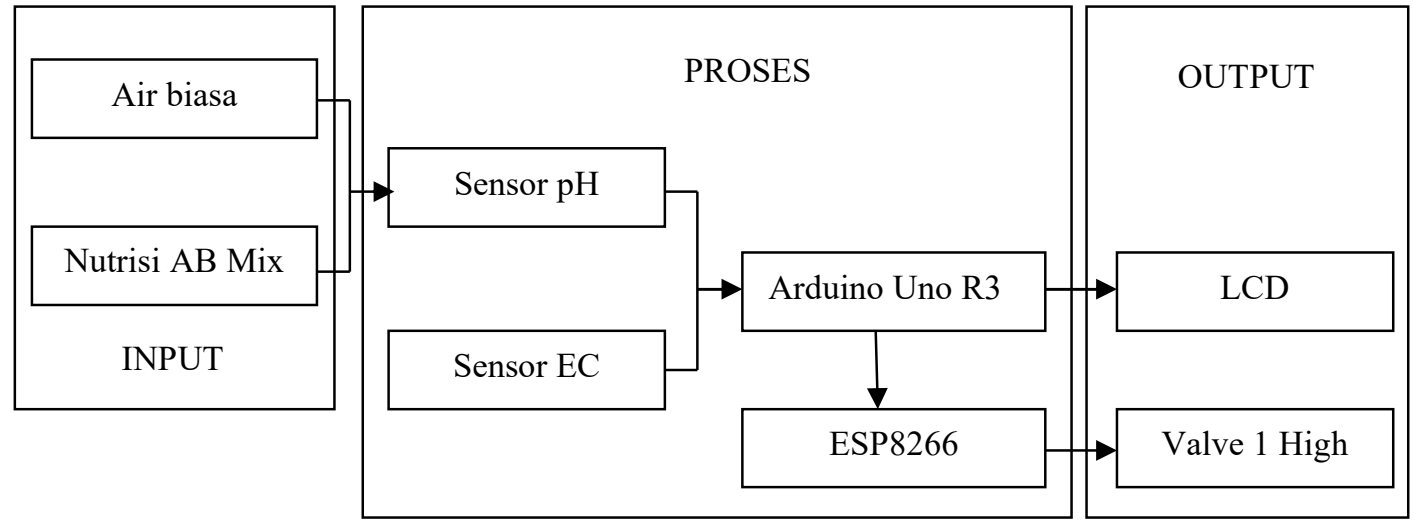

Gambar 2. Diagram blok sistem

Penjelasan dari Gambar 1 adalah sebagai berikut. Komunikasi antara smartphone dengan modul ESP8266 dilakukan melalui jaringan internet. Smartphone melalui aplikasi blynk mengirim data ke internet ke server blynk. Data dari server blynk kemudian diteruskan ke modul ESP8266 melalui jaringan wifi. Sampai di modul ESP8266 data tersebut digunakan untuk mengendalikan kecepatan dari putaran angin / blower dari Penyejuk ruangan.

\subsection{Flowchart Deteksi $p H$ dan EC}

Flowchart perlu di sesuaikan dengan perangkat keras yang dibuat agar program terstuktur dan jelas. Flowchart pembuatan purwarupa deteksi pH dan EC dapat terlihat pada gambar 3 sebagai berikut.

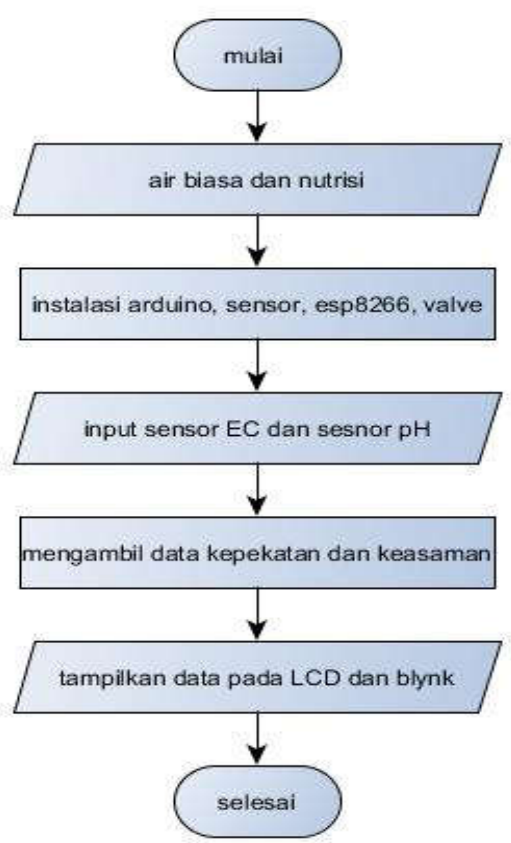

Gambar 3. Flowchart Deteksi pH dan EC 


\subsection{Perancangan Mekanik}

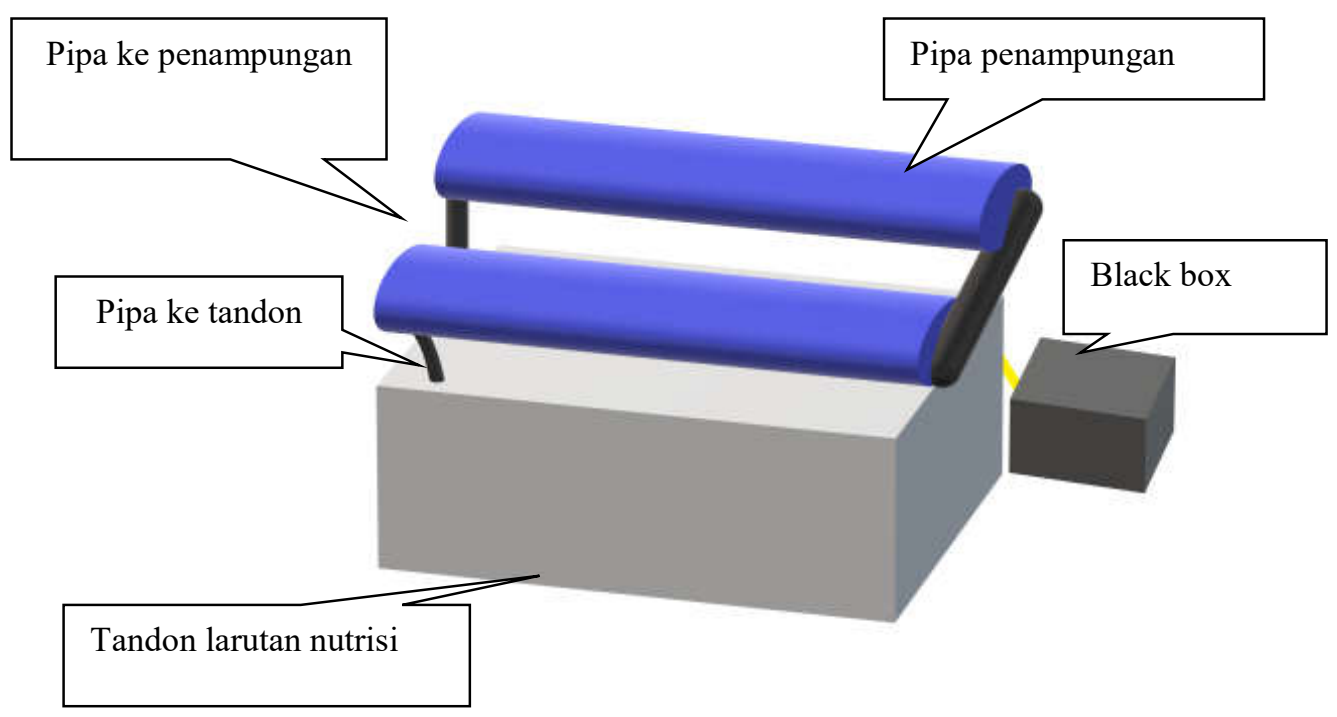

Gambar 4. Perancangan Mekanik Tampak Keseluruhan

Gambar 4 perancangan mekanik dibuat untuk membantu dalam membuat purwarupa alat. Perancangan mekanik juga dapat mendukung kinerja alat. Pada penelitian ini menggunakan pipa pralon untuk membuat pipa penampungan hidroponik pada purwarupa deteksi $\mathrm{pH}$ dan EC larutan nutrisi. Perancangan mekanik dapat dilihat pada gambar 4 adalah perancangan mekanik pipa penampungan hidroponik tampak keseluruhan meliputi bak tanam, peletakan sensor, pompa air, black box, bak penampungan air.

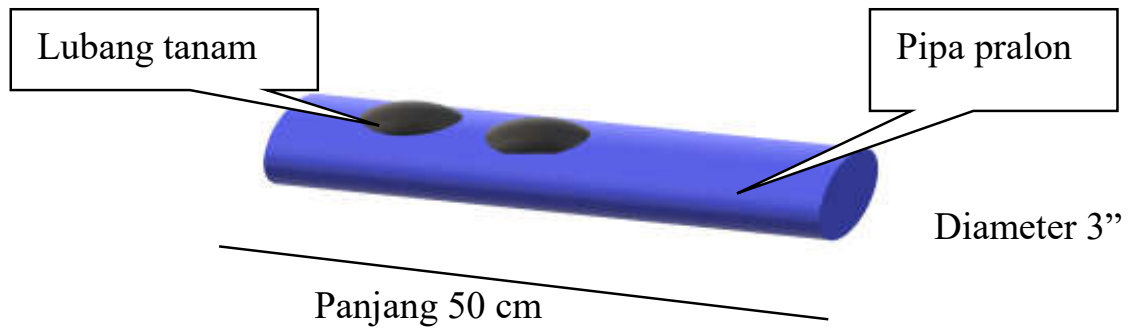

Gambar 5. Perancangan Mekanik Pipa Penampungan

\subsection{Skema Perancangan Komponen Keseluruhan}

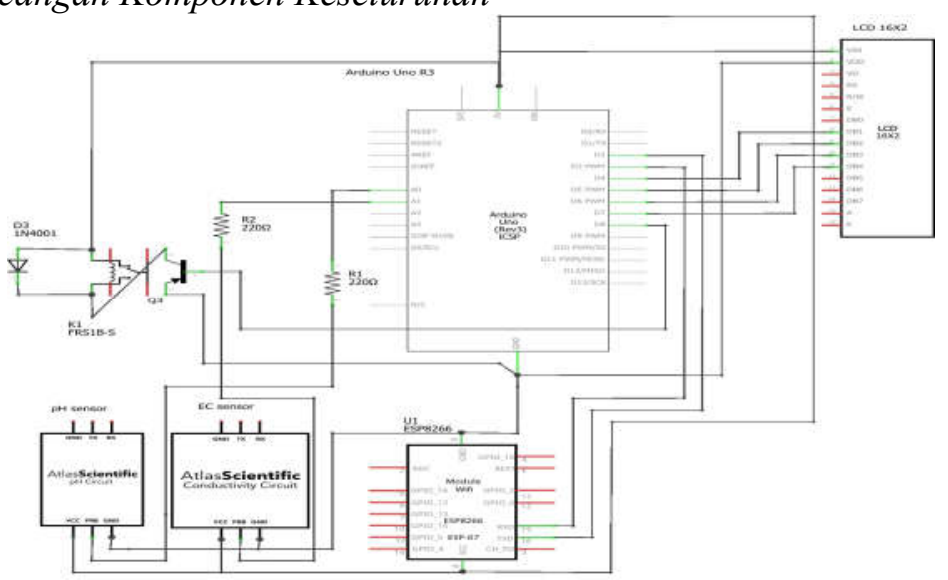

Gambar 6. Skema Perancangan Komponen Keseluruhan 


\section{HASIL DAN PEMBAHASAN}

\subsection{Perakitan Sensor Deteksi Keasaman dan Kepekatan Air}

Berdasarkan perancangan yang telah dibuat maka perakitan sensor pendeteksi keasaman dan kepekatan air pada bak tanam membutuhkan sensor $\mathrm{pH}$ yang terhubung dengan arduino uno R3 seperti terlihat pada gambar 7 berikut. Toleransi nilai keasaman air anatara 5,5-7 (pH normal), toleransi nilai kepekatan air anatara $1,5 \mathrm{~ms} / \mathrm{cm}-2,0 \mathrm{~ms} / \mathrm{cm}$ (jenis tanaman sayur).

Hasil deteksi kepekatan ini digunakan sebagai pengaktifan solenoid valve untuk menstabilkan kadar larutan nutrisi didalam bak penampungan. Jika kadar kepekatan tertalu tinggi maka akan bersifat keras atau mengalami pengendapan sehingga tidak ada penyerapan nutrisi oleh akar tanaman hidroponik. Komponen sensor keasaman air dan kepekatan air dapat dilihat pada Tabel 1 dan 2 .

Tabel 1 Komponen Sensor Keasaman Air

\begin{tabular}{|c|c|c|c|c|}
\hline Rangkaian & Komponen & Kaki & \multicolumn{2}{|c|}{ Keterangan Pin } \\
\hline Sensor & Sensor $\mathrm{pH}$ & 1 & Vcc & Vcc 5v \\
\cline { 3 - 5 } $\begin{array}{c}\text { Keasaman dan } \\
\text { kebasaan }\end{array}$ & & 2 & Prb & A0 \\
\cline { 3 - 5 } & & 3 & Gnd & Gnd \\
\hline
\end{tabular}

Tabel 2 Komponen Sensor Kepekatan Air

\begin{tabular}{|c|c|c|c|c|}
\hline Rangkaian & Komponen & Kaki & \multicolumn{2}{|c|}{ Keterangan Pin } \\
\hline \multirow{2}{*}{$\begin{array}{c}\text { Sensor Kepekatan } \\
\text { air }\end{array}$} & Sensor EC & 1 & Vcc & Vcc 5v \\
\cline { 3 - 5 } & & 2 & Prb & A1 \\
\cline { 3 - 5 } & & 3 & Gnd & Gnd \\
\hline
\end{tabular}

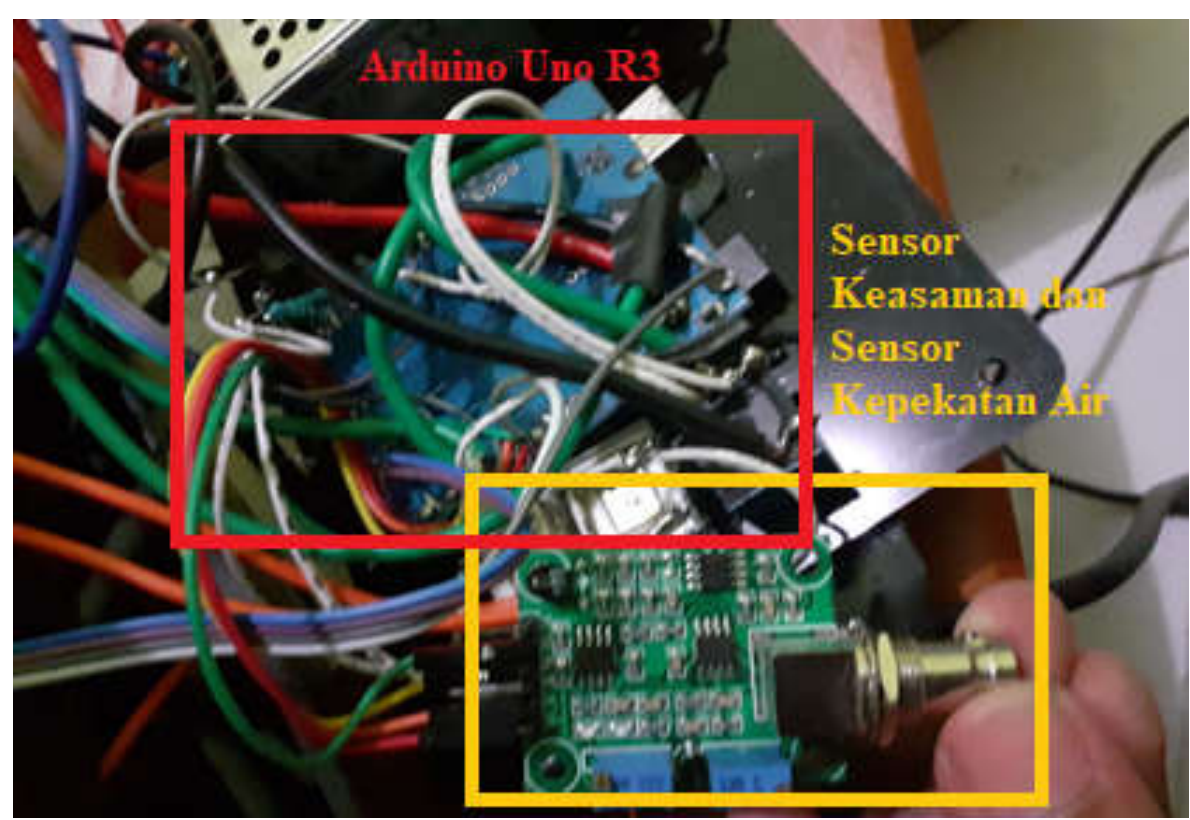

Gambar 7. Perakitan Sensor Deteksi Keasaman dan Kepekatan Air

Pada Tabel 1 dan 2 menunjukan sensor keasaman dan kepekatan air terhubung dengan arduino uno R3 dengan kaki 1 terhubung dengan Ground, kaki 2 atau Prb terhubung dengan Analog 0 dan Analog 1, kaki 3 terhubung dengan tegangan atau vcc.

\subsection{Pengujian Sensor Deteksi Keasaman dan Kepekatan Air}

Pengujian sensor $\mathrm{pH}$ dilakukan untuk menguji fungsi sensor alat tersebut dengan membaca kadar keasaman dan kadar kepekataan air. Ketika kadar kepekataan air dibawah atau diatas batas toleransi, maka akan menghasilkan output yang akan di tampilkan di LCD dan 
aplikasi mobile. Jika kepekatan larutan yang terdeteksi diatas $2,0 \mathrm{~ms} / \mathrm{cm}$ maka akan muncul keterangan di LCD untuk membuang larutan nutrisi. Kemudian pada aplikasi mobile menekan push button buka pompa maka Solenoid valve akan menyalakan pompa dan melakukan penggosongan tandon larutan nutrisi. Percobaan deteksi keasaman dan kepekatan karutan nutrisi seperti gambar 4.11 berikut. Kepekatan larutan nutisi untuk jenis sayuran berada dibatas toleransi $1,5-2,0 \mathrm{~ms} / \mathrm{cm}$. jika nilai kepekatan yang terdeteksi dibawah $1,5 \mathrm{~ms} / \mathrm{cm}$ akan muncul keterangan di LCD untuk menambah nutrisi untuk menjaga pertumbuhan dan perkembangan tanaman hidroponik.

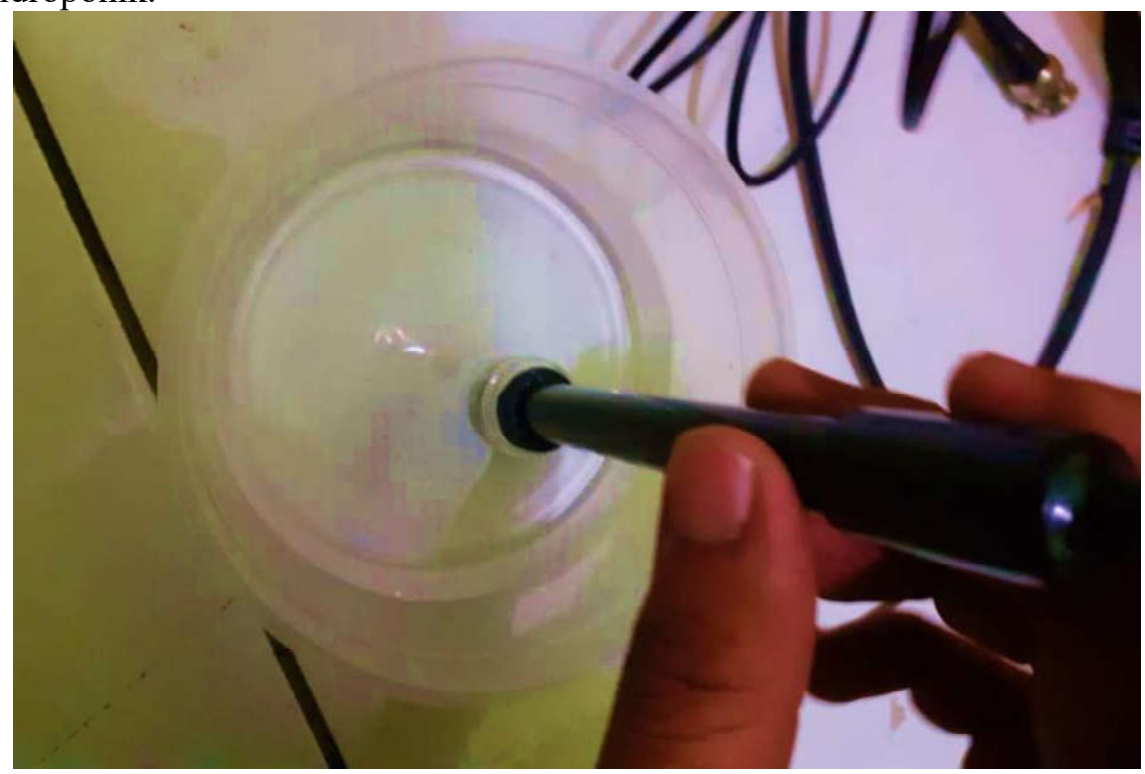

Gambar 8. Pengujian Sensor Keasaman dan Kepekatan Air

Hasil pengujian bisa diketahui pada Tabel 3 pengujian kadar keasaman dan kadar kepekatan air dilakukan dengan 10 kali percobaan untuk mengetahui kinerja sensor keasaman dan sesnor kepekatan larutan ketika air $1000 \mathrm{ml}$ dicampurkan nutrisi $\mathrm{AB}$ mix.

Tabel 3 Hasil Pengujian Kadar Keasaman dan Kepekatan Air

\begin{tabular}{|l|l|c|c|}
\hline \multirow{2}{*}{ No } & Jenis Larutan & \multicolumn{2}{|c|}{ Sensor Ph } \\
\cline { 3 - 4 } & & Keasaman & Kepekatan \\
\hline 1 & Air $1000 \mathrm{ml}$ & 6 & $1,2 \mathrm{~ms} / \mathrm{cm}$ \\
\hline 2 & Air $1000 \mathrm{ml}+$ Nutrisi AB Mix $10 \mathrm{ml}$ & 7 & $1,5 \mathrm{~ms} / \mathrm{cm}$ \\
\hline 3 & Air $1000 \mathrm{ml}+$ Nutrisi AB Mix $20 \mathrm{ml}$ & 7 & $1,7 \mathrm{~ms} / \mathrm{cm}$ \\
\hline 4 & Air $1000 \mathrm{ml}+$ Nutrisi AB Mix $30 \mathrm{ml}$ & 8 & $1,8 \mathrm{~ms} / \mathrm{cm}$ \\
\hline 5 & Air $1000 \mathrm{ml}+$ Nutrisi AB Mix $40 \mathrm{ml}$ & 8 & $2,0 \mathrm{~ms} / \mathrm{cm}$ \\
\hline 6 & Air $1000 \mathrm{ml}+$ Nutrisi AB Mix $50 \mathrm{ml}$ & 9 & $2,1 \mathrm{~ms} / \mathrm{cm}$ \\
\hline 7 & Air $1000 \mathrm{ml}+$ Nutrisi AB Mix $60 \mathrm{ml}$ & 9 & $2,1 \mathrm{~ms} / \mathrm{cm}$ \\
\hline 8 & Air $1000 \mathrm{ml}+$ Nutrisi AB Mix $80 \mathrm{ml}$ & 10 & $2,2 \mathrm{~ms} / \mathrm{cm}$ \\
\hline 9 & Air $1000 \mathrm{ml}+$ Nutrisi AB Mix $90 \mathrm{ml}$ & 10 & $2,3 \mathrm{~ms} / \mathrm{cm}$ \\
\hline 10 & Air $1000 \mathrm{ml}+$ Nutrisi AB Mix $100 \mathrm{ml}$ & 12 & $2,5 \mathrm{~ms} / \mathrm{cm}$ \\
\hline
\end{tabular}

Ketika mengukur tingkat kepekatan larutan nutrisi hidroponik biasanya menggunakan alat ukur TDS meter dan biasanya menggunakan satuan ppm, dan pada penelitian skripsi ini menggunakan EC dengan satuan $\mathrm{ms} / \mathrm{cm}$. penulis menggunakan EC karna nilai yang di deteksi lebih akurat, sedangkan dengan menggunkan satuan ppm akan berbeda nilainya setiap penggukuran. Perbedaan tersebut dikarenakan satuan ppm adalah hasil konversi dari nilai EC. Konversi ini dibagi menjadi 3 metode yaitu sebagai berikut. 
a. Metode Hanna :

Nilai EC $1,2 \mathrm{~ms} / \mathrm{cm} \rightarrow \frac{1,2 \times 1000}{2}=600 \mathrm{ppm}$

Nilai EC $1,5 \mathrm{~ms} / \mathrm{cm} \rightarrow \frac{1,5 \times 1000}{2}=750 \mathrm{ppm}$

Nilai EC $1,7 \mathrm{~ms} / \mathrm{cm} \rightarrow \frac{1,7 \times 1000}{2}=850 \mathrm{ppm}$

Nilai EC $1,8 \mathrm{~ms} / \mathrm{cm} \rightarrow \frac{1,8 \times 1000}{2}=900 \mathrm{ppm}$

Nilai EC $2,0 \mathrm{~ms} / \mathrm{cm} \rightarrow \frac{2,0 \times 1000}{2}=1000 \mathrm{ppm}$

Nilai EC $2,1 \mathrm{~ms} / \mathrm{cm} \rightarrow \frac{2,1 \times 1000}{2}=1050 \mathrm{ppm}$

Nilai EC 2,2 ms $/ \mathrm{cm} \rightarrow \frac{2,0 \times 1000}{2}=1100 \mathrm{ppm}$

Nilai EC $2,3 \mathrm{~ms} / \mathrm{cm} \rightarrow \frac{2,3 \times 1000}{2}=1150 \mathrm{ppm}$

Nilai EC $2,5 \mathrm{~ms} / \mathrm{cm} \rightarrow \frac{2,5 \times 1000}{2}=1250 \mathrm{ppm}$

b. Metode Truncheon

Nilai EC $1,2 \mathrm{~ms} / \mathrm{cm} \rightarrow \frac{1,2 \times 1000}{1,4285}=840 \mathrm{ppm}$

Nilai EC $1,5 \mathrm{~ms} / \mathrm{cm} \rightarrow \frac{1,5 \times 1000}{1,4285}=1050 \mathrm{ppm}$

Nilai EC $1,7 \mathrm{~ms} / \mathrm{cm} \rightarrow \frac{1,7 \times 1000}{1,4285}=1190 \mathrm{ppm}$

Nilai EC $1,8 \mathrm{~ms} / \mathrm{cm} \rightarrow \frac{1,8 \times 1000}{1,4285}=1260 \mathrm{ppm}$

Nilai EC $2,0 \mathrm{~ms} / \mathrm{cm} \rightarrow \frac{2,0 \times 1000}{1,4285}=1400 \mathrm{ppm}$

Nilai EC $2,1 \mathrm{~ms} / \mathrm{cm} \rightarrow \frac{2,1 \times 1000}{1,4285}=1470 \mathrm{ppm}$

Nilai EC $2,2 \mathrm{~ms} / \mathrm{cm} \rightarrow \frac{2,2 \times 1000}{2,4285}=1540 \mathrm{ppm}$

Nilai EC $2,3 \mathrm{~ms} / \mathrm{cm} \rightarrow \frac{2,3 \times 1000}{1,4285}=1610 \mathrm{ppm}$

Nilai EC $2,5 \mathrm{~ms} / \mathrm{cm} \rightarrow \frac{2,5 \times 1000}{1,4285}=1750 \mathrm{ppm}$ 
c. Metode Eutech

Nilai EC $1,2 \mathrm{~ms} / \mathrm{cm} \rightarrow \frac{1,2 * 1000}{1,5625}=768 \mathrm{ppm}$

Nilai EC $1,5 \mathrm{~ms} / \mathrm{cm} \rightarrow \frac{1,5 \times 1000}{1,5625}=960 \mathrm{ppm}$

Nilai EC $1,7 \mathrm{~ms} / \mathrm{cm} \rightarrow \frac{1,7 \times 1000}{1,5625}=1088 \mathrm{ppm}$

Nilai EC $1,8 \mathrm{~ms} / \mathrm{cm} \rightarrow \frac{1,8 \times 1000}{1,5625}=1152 \mathrm{ppm}$

Nilai EC 2,0 ms $/ \mathrm{cm} \rightarrow \frac{2,0 \times 1000}{1,5625}=1280 \mathrm{ppm}$

Nilai EC $2,1 \mathrm{~ms} / \mathrm{cm} \rightarrow \frac{2,1 \times 1000}{1,5625}=1344 \mathrm{ppm}$

Nilai EC $2,2 \mathrm{~ms} / \mathrm{cm} \rightarrow \frac{2,2 x 1000}{1,5625}=1408 \mathrm{ppm}$

Nilai EC $2,3 \mathrm{~ms} / \mathrm{cm} \rightarrow \frac{2,3 * 1000}{1,5625}=1472 \mathrm{ppm}$

Nilai EC $2,5 \mathrm{~ms} / \mathrm{cm} \rightarrow \frac{2,5 * 1000}{1,5625}=1600 \mathrm{ppm}$

\subsection{Hasil Pengujian Aplikasi Mobile}

Ketika sensor mendeteksi kondisi air didalam bak tanam maka aplikasi mobile sebagai user interface akan menampilkan kadar keasaman dan kadar kepekatan air. Pada aplikasi mobile juga terdapat push button yang berfungsi sebagai pengguras air di dalam tandon penampungan hingga ketinggian air atau " $\mathrm{h} "=0 \mathrm{~cm}$. Tampilan pada aplikasi mobile dapat dilihat pada Gambar 9 berikut. Pengujian pada aplikasi mobile hanya bisa dilakukan apa bisa terhubung dengan jaringan internet yang stabil, sehingga sangat mempengaruhi delay nilai $\mathrm{pH}$, nilai EC yang terbaca serta buka atau tutup pompa.

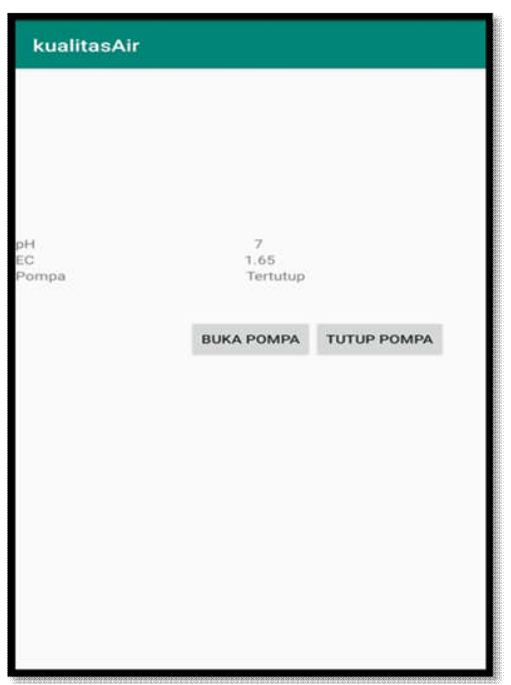

(a)

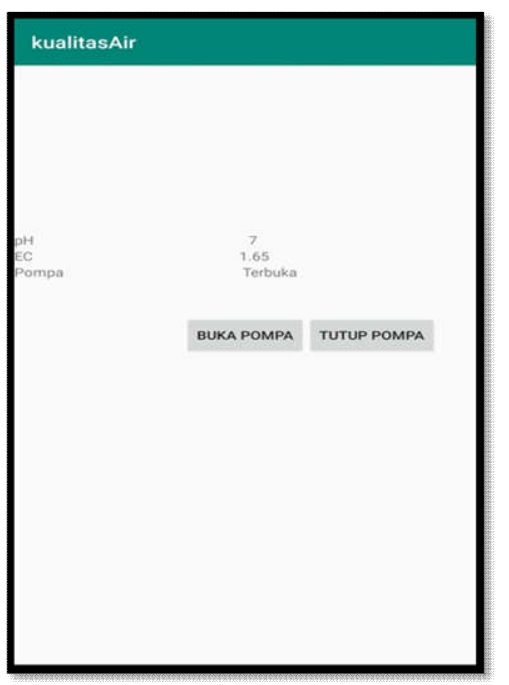

(b)

Gambar 9. (a) Tampilan Awal Pengujian Aplikasi Mobile (b) Tampilan Buka Pompa Untuk Penggosongan Tandon Penampungan 


\subsection{Pembahasan}

Tahapan ini purwarupa alat deteksi $\mathrm{pH}$ dan EC larutan nutrisi hidroponik yang telah selesai dalam perancangan di bagian sebelumnya dan sudah diimplementasikan dalam perakitan komponen serta telah dilakukan pengujian dan diperlihatkan hasil pengujian maka dari itu cara penggunaan alat deteksi Ph dan EC dapat dilihat pada Gambar 10 sebagai berikut.

1. Menyalakan catu daya.

2. Memasukan air sumur atau air biasa dan nutrisi AB Mix kedalam bak tanam.

3. Menunggu proses sensing larutan nutrisi.

4. Setelah sensing larutan nutrisi selesai LCD dan aplikasi mobile akan menampilkan data informasi keasaman air, dan kepekatan air.

5. Pada LCD akan menerangkan nilai $\mathrm{pH}$ dan nilai EC yang terbaca.

6. Jika penggiat hidropnik akan mengguras bak tanam, dengan mengklik push button pada aplikasi mobile, dan solenoid valve output aktif hingga ketinggian didalam bak tanam sama dengan $0 \mathrm{~cm}$.

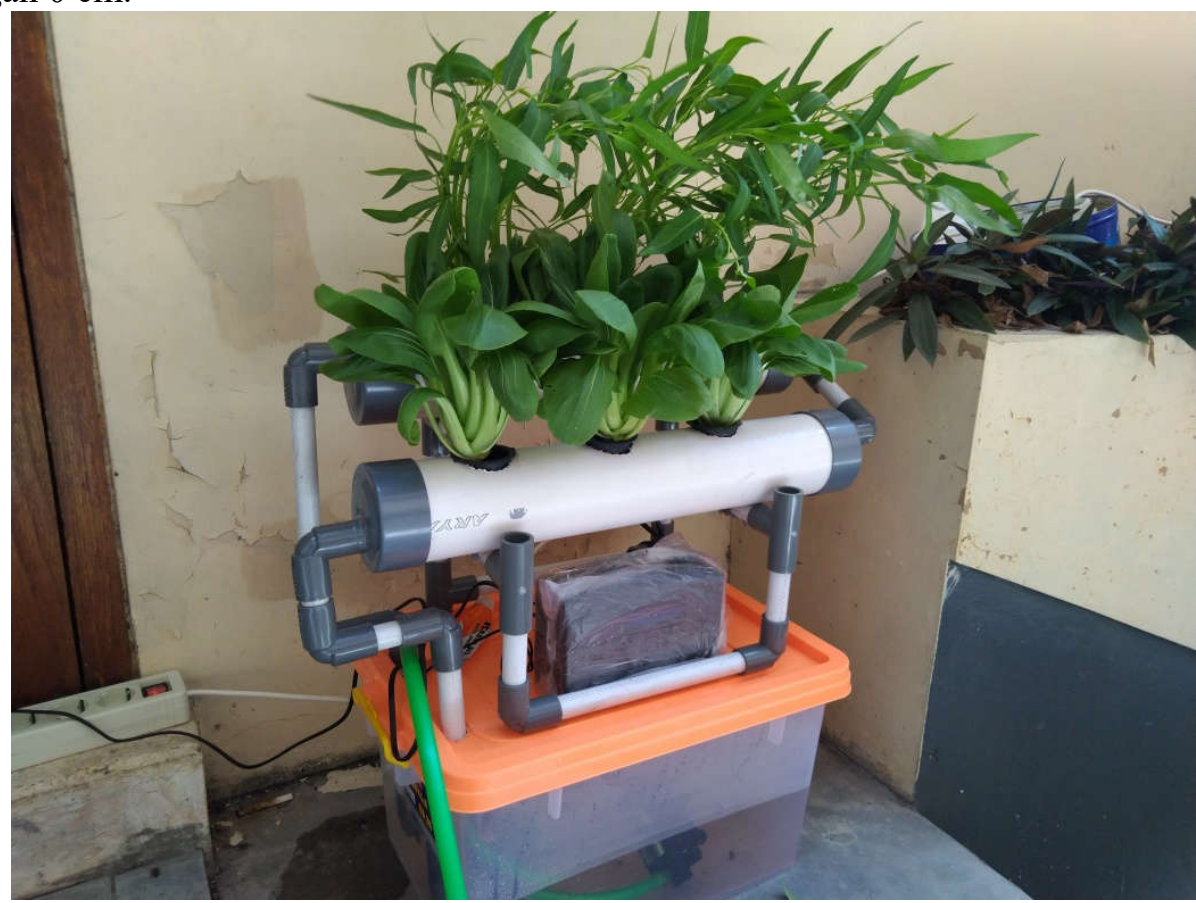

Gambar 10. Purwarupa Deteksi pH dan EC Larutan Nutrisi Hidroponik Berbasis IoT (Internet of Things)

\section{KESIMPULAN}

Kesimpulan dari hasil pengujian dan penelitian purwarupa deteksi pH dan EC larutan nutrisi hidroponik berbasis IoT (Internet of Things) yang telah dilakukan, dapat disimpulkan bahwa alat deteksi $\mathrm{pH}$ dan EC otomatis telah berhasil dirancang dan dibuat menggunakan arduino uno R3 sebagai pusat pengendali dengan sensor $\mathrm{pH}$ sebagai pendeteksi keasaman dan kepekatan air didalam bak tanam. Alat akan terus bekerja selama terhubung dengan arus listrik, saat tidak terhubung dengan arus listrik maka aliran larutan nutrisi ke pipa penampungan akan berhenti dan berkurangnya larutan nutrisi sesuai tingkat penyerapan tanaman terhadap larutan nutrisi. Data yang masuk ke aplikasi mobile mengandalkan kekuatan sinyal hotspot WiFi untuk megirimkan data keasaman, kepekatan larutan nutrisi, dan kontrol pompa penggurasan. 


\section{SARAN}

Alat ini dapat dikembangkan lebih lanjut sehingga bisa menjadi sempurna, beberapa pengembangan yang bisa dilakukan diantaranya. Pada purwarupa yang telah dibuat diambil data kepekatan larutan untuk menstabilkan kadar larutan nutrisi, maka diharapkan kepada pengembang alat maupun sistem agar dapat menggunakan data keasaman juga untuk menstabilkan kadar larutan nutrisi. Serta dapat menambahkan aspek hidroponik yang lainnya seperti suhu, kondisi perakaran tanaman. Sistem hanya menggunakan android sebagai panel informasi realtime, maka diharapkan pada pengembang untuk bisa membuat panel informasi di operating system yang lain. Pencampuran larutan nutrisi AB Mix masih dilakukan secara manual, maka diharapkan pada pengembang menambahkan takaran alat otomatis untuk mencampurkan nutrisi A dan nutrisi B.

\section{DAFTAR PUSTAKA}

[1] Bruce, P. d. 2014. Software Engineering: A Practitioner's Approach.

[2] Karina, N. 2017. Perancangan Sistem Alir Larutan Nutrisi Otomatis pada Tanaman Hidroponik dengan Mikrokontroller Arduino berbasis Android. Retrieved May 5, 2019, http://repositori.usus.ac.id/handle/123456789/2237

[3] Morgan, L. 2000. The Best of the Growing Edge 2, the Basic Elements of Hydroponic. Corvallis (USA): New Moon Publishing Inc.

[4] Nazruddin. 2012. Pemrograman Aplikasi Mobile Smartphone dan Tablet PC Berbasis Android. Bandung: Informatika.

[5] Suprianto. 2015. Pengertian dan Prinsip Kerja Solenoid Valve. http://blog.unnes.ac.id/antosupri/pengertian-dan-prinsip-kerja-solenoid-valve/, diakses 30 Juli 2019

[6] Ulfah, R. 2018. Pengukur Electro Conductivity Pada Larutan Nutrisi Hidroponik Berbasis Mikrokontroler ATMega8535.

http://repositori.usu.ac.id/bitstream/handle/123456789/8701/160821014.pdf, diakses 26 Juli 2019 